\title{
Design features of bimetallic bridges
}

\author{
Aleksander Makarov ${ }^{1}$ and Sergey Kalinovsky ${ }^{2, *}$ \\ ${ }^{1}$ Volgograd State Technical University (VSTU), Survey and design of transport structures, 400074, \\ Akademicheskaya St. 1, Volgograd, Russian Federation \\ ${ }^{2}$ Volgograd State Technical University (VSTU), Hydraulic and Earthwork Structures Department, \\ 400074, Akademicheskaya St. 1, Volgograd, Russian Federation
}

\begin{abstract}
The Design and construction of metal bridges is the most reasonable from the structural and technological point of view, as well as from the standpoint of the implementation of non-standard engineering and spatial solutions. The weak point most often in this case is the efficiency of construction. To improve economic efficiency, it is recommended to use metal structures, the most loaded elements of the beams in which should be made of high-strength steels, and all other conventional rolled steel. Spans of a continuous plate should be designed in such a way that the spans moments are equal. The authors propose to assign the values of spans in accordance with their effective ratio and design the span structure of the three types of standard blocks.
\end{abstract}

\section{Introduction}

The main structural types of bridge structures are split and continuous beam bridges. On the territory of the Russian Federation and the former Soviet Union the most common bridges split design schemes. During their construction, the main material has traditionally been precast concrete. However, do not forget that the metal bridge structures were built everywhere since the second half of the nineteenth century. At the same time, it is important to note that the gold Fund of bridge construction is made up of metal bridges, in particular the railway bridge over the Yenisei river by Professor L. D. Proskuryakov, for which the author was awarded a Large gold medal at the Paris world exhibition in 1900 [1].

The reason for the wide spread of precast concrete bridges was the presence of a powerful production base for the production of standard structures and parts for civil, industrial and transport construction. The industrial approach provided both reduction of terms and ease of installation, and reduction of estimated cost of works. However, along with the advantages of precast concrete bridge structures, they have significant disadvantages: the complexity of recycling structures, the inability to reuse the material, the lack of variability in design solutions. The appearance of the engineering structure and the size of the covered span also became strictly regulated, preventing the creation of a unique object [2].

\footnotetext{
* Corresponding author: sk0522@yandex.com
} 
In comparison with reinforced concrete structures, metal bridges and overpasses are devoid of the above disadvantages [3]. The possibility of overlapping large spans and ease of metal recycling make the bridge structure more attractive to the designer. However, the use in bridge construction of rolled steel of different brands, i.e. expensive materials, requiring a large amount of resources defines the concept of efficiency of the structure. The efficiency of the structure, in turn, is determined by the effective use of the material, so that the operating stresses normal, tangential and given in all sections of the structure would be the maximum from the effects of full loads.

\section{Methods for improving the efficiency of bridge structures}

Design efficiency can be improved in several ways [4]. The first method, which consists in the fact that the belts of I-beams are made composite, is widely used in modern bridge construction. With such design solutions, the width and thickness of the steel sheets of the belt are selected so that the maximum normal stresses in them do not exceed the permissible values. When designing a belt, it is necessary to avoid the occurrence of stress concentrators and to prevent abrupt changes in the cross-sectional area of the belts, performing a smooth transition, as shown in figure 1.

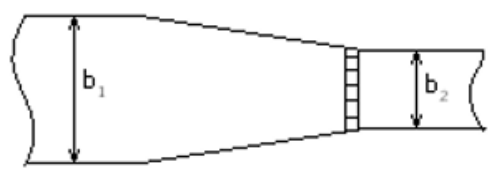

a)

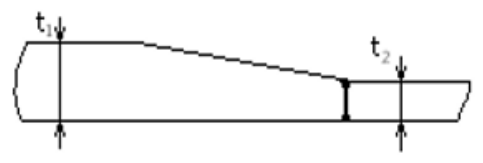

b)

Fig. 1. Changing the sheets of the belt a) width, b) thickness

The disadvantage of the composite sections of the beams of bridge structures is their increased complexity associated with the need to cut metal sheets and their welding.

The second method is associated with the use in the manufacture of beams of two different strength characteristics of steel grades. In this case, the superstructure is called bimetallic. Beams of this structural type have less weight and less complexity of manufacturing.

Currently, due to the lack of design experience, such superstructures are not widely used in the practice of Russian bridge construction. The bimetallic superstructure is significantly more profitable than the composite one in those cases when the number of connections inside one structural unit will be used as little as possible.

Traditionally, bridge metal structures are made of sheet and shaped hot-rolled steel. Used as plates and wide universal steel, and shaped steel angle, beam, channel, strip, and circular cross-section [3,5,6]. Bridge structures are subjected to dynamic loads [7], which necessitates the need to bring them into compliance with technological requirements, and therefore, for the manufacture of their elements should be used high-quality low-alloy Converter steel (SP 35.13330.2011 Bridges and pipes [8]). These include the following grades: 16D, 15HSND, 10KHSND made in accordance with [9] and 15G2AFDps, 14G2AFD made in accordance with [10]. The chemical composition of bridge steels is given in tables 1 and 2 .

Table 1. The chemical composition of some grades of bridge steels [9]

\begin{tabular}{|l|c|c|c|c|c|c|c|c|}
\hline Steel & $\mathbf{C}$ & $\mathbf{S i}$ & $\mathbf{M n}$ & $\mathbf{C r}$ & $\mathbf{N}$ & $\mathbf{C u}$ & $\mathbf{P}$ & $\mathbf{S}$ \\
\hline $16 \mathrm{D}$ & $0.1-0,18$ & $0.12-0.25$ & $0.4-0.7$ & 0.3 & 0.3 & $0.2-0.35$ & 0.035 & 0.04 \\
\hline
\end{tabular}




\begin{tabular}{|l|c|c|c|c|c|c|c|c|}
\hline 15HSND & $0.12-0.18$ & $0.4-0.7$ & $0.4-0.7$ & $0.6-0.9$ & $0.3-0.6$ & $0.2-0.4$ & 0.035 & 0.035 \\
\hline 10KHSND & 0.12 & $0.8-1.1$ & $0.5-0.8$ & $0.6-0.9$ & $0.5-0.8$ & $0.4-0.6$ & 0.035 & 0.035 \\
\hline
\end{tabular}

Table 2. The chemical composition of some grades of bridge steels [10]

\begin{tabular}{|c|c|c|c|c|c|c|c|}
\hline \multicolumn{1}{|c|}{ Steel } & $\mathbf{C}$ & $\mathbf{S i}$ & $\mathbf{M n}$ & $\mathbf{C r}$ & $\mathbf{N}$ & $\mathbf{C u}$ & $\mathbf{B}$ \\
\hline 15G2AFDps & $0.12-0.18$ & 0.17 & $1.2-1.6$ & 0.3 & 0.3 & $0.2-0.4$ & $0.08-0.15$ \\
\hline 14G2AFD & $0.12-0.18$ & $0.3-0.6$ & $1.2-1.6$ & 0.4 & 0.3 & $0.15-0.3$ & $0.07-0.12$ \\
\hline
\end{tabular}

To indicate steel grades, numbers and letters mean: two - digit numbers on the left - the approximate average carbon content in hundredths of a percent, letters to the right of the numbers: G - manganese, C - silicon, X - chromium, N - Nickel, D - copper, f - vanadium, $\mathrm{B}$ - niobium, a - nitrogen, $\mathrm{P}$ - phosphorus, numbers after the letters - the approximate content of the corresponding element in whole percent, the letters "PS" at the end of the brand-semi-calm steel.

The tensile strength characteristics of the sheet metal in the above mentioned steels are given in table 3 .

Table 3. Mechanical characteristics of rolled steel sheet

\begin{tabular}{|l|c|c|c|}
\hline \multicolumn{1}{|c|}{ Steel grade } & Time resistance, MPa & Yield strength, MPa & $\begin{array}{c}\text { Relative } \\
\text { lengthening, \% }\end{array}$ \\
\hline $16 \mathrm{D}$ & $375-510$ & 225 & 26 \\
\hline $15 \mathrm{HSND}$ & $470-670$ & 335 & 19 \\
\hline 10 KHSND & $530-670$ & 390 & 19 \\
\hline 15G2AFDps & 540 & 390 & 19 \\
\hline 14G2AFD & 540 & 390 & 19 \\
\hline
\end{tabular}

In addition to the above and traditionally used in the bridge construction of steels, for the manufacture of structural elements of bimetallic bridges can be used carbon and low-alloy steels of high strength, the chemical composition of which is specified in the table 4 [11].

Table 4. Chemical composition of some grades of carbon low alloy steels [11]

\begin{tabular}{|c|c|c|c|c|c|c|c|c|}
\hline Steel & $\mathbf{C}$ & $\mathbf{S i}$ & $\mathbf{M n}$ & $\mathbf{P}$ & $\mathbf{S}$ & $\mathbf{N}$ & $\mathbf{B}$ & $\mathbf{C r}$ \\
\hline S890QL & 0.20 & 0.80 & 1.70 & 0.020 & 0.010 & 0.015 & 0.005 & 1.50 \\
\hline Steel & $\mathrm{Cu}$ & $\mathrm{Mo}$ & $\mathrm{Nb}$ & $\mathrm{Ni}$ & $\mathrm{Ti}$ & $\mathrm{V}$ & $\mathrm{Zr}$ & \\
\hline S890QL & 0.50 & 0.70 & 0.06 & 2.0 & 0.05 & 0.12 & 0.15 & \\
\hline
\end{tabular}

Mechanical characteristics of S890QL sheet metal and some similar ones are presented in table 5 . 
Table 5. Mechanical characteristics of rolled sheet of the brand S890QL

\begin{tabular}{|l|c|c|c|}
\hline \multicolumn{1}{|c|}{ Steel grade } & Time resistance, MPa & Yield strength, MPa & $\begin{array}{c}\text { Relative } \\
\text { lengthening, \% }\end{array}$ \\
\hline S890QL & $880-1100$ & $830-890$ & 11 \\
\hline S890Q & $880-1100$ & $830-890$ & 11 \\
\hline S890QL1 & $880-1100$ & $830-890$ & 11 \\
\hline
\end{tabular}

Rolled steel in table 5 is produced according to the European production standard EN 10025-6 [12]. The symbols used in the stamps of steels according to European production standards, show that the Q - test for energy impact strength carried out at a temperature of $20^{\circ} \mathrm{C}$; QL - test for energy impact strength carried out at a temperature of $-40^{\circ} \mathrm{C}$; QL1 - test for energy impact strength carried out at a temperature of $-60^{\circ} \mathrm{C}$. This standard specifies the technical conditions for hot-rolled structural steels quenching and following tempering. Hardening is the process of heating steel to a temperature above the critical point and then rapidly cooling with water, oil or water-air mixture. After hardening, the steel becomes hard and brittle, with strong internal stresses. To improve performance shall be the subsequent vacation. Tempering is the process of reheating, but below the critical point. This operation increases the ductility of steel, which makes it possible to obtain steel with a good ratio of strength and ductility. This well-exposed to welding, bending and so easy to work with. The improvement of quenching and tempering processes allowed the metallurgical industry to produce sheet steel with a yield strength of up to $1300 \mathrm{MPa}$, which is more than 4 times higher than the characteristics of the main grades of structural steels. The use of such steels for the manufacture of elements of superstructures will facilitate the design and reduce the complexity of the work. However, the increase in the cost of the metal in this case is a significant drawback.

\section{Results and Discussion}

The metal superstructure can be designed to be cost-effective only if the use of durable metal in sections with the greatest effort. This requires that, in all spans, the spans be equal. As an example, consider the calculation of the most widely used three-span continuous span structure of an all-metal bridge loaded with a uniform load $q_{\text {const }}$ (eigenweight). 


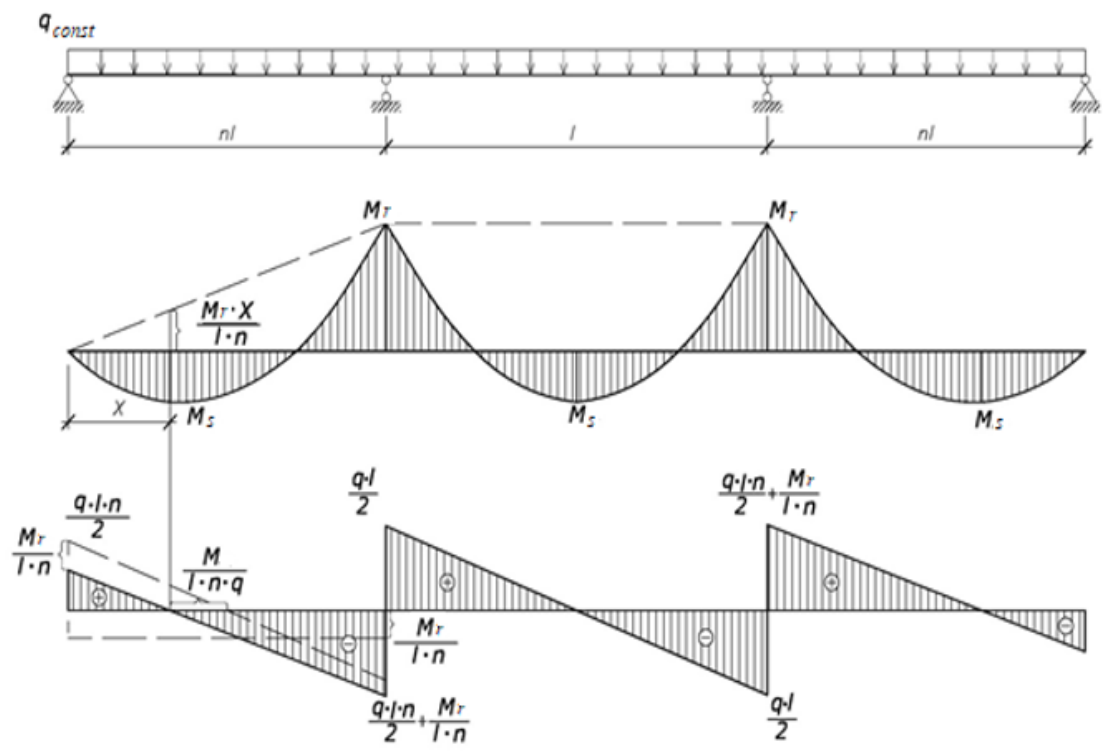

Fig. 2. Scheme of continuous span structure with aligned span bending moments

The supporting moment will be:

$$
M_{r}=-\frac{q \cdot l^{2}\left(n^{3}+1\right)}{4(2 \cdot n+3)}
$$

In the central span, the maximum span moment acts in the middle section, and in the extreme is spaced from the middle by the value $\frac{M_{r}}{l \cdot n \cdot q}$, as shown in figure. 2

We equate the maximum bending moments in the extreme and average spans and obtain the following expression:

$$
\frac{q l^{2}}{8}-\frac{q l^{2}\left(n^{3}+1\right)}{4 \cdot(2 \cdot n+3)}=\left(\frac{q l \cdot n}{2}-\frac{M_{r}}{l \cdot n}\right) \cdot\left(\frac{q l}{2}-\frac{M_{r}}{l \cdot n \cdot q}\right)-\frac{q}{2}\left(\frac{l \cdot n}{2}-\frac{M_{r}}{l \cdot n \cdot q}\right)^{2}
$$

Substituting the value of $M_{r}$ and solving the transcendental equation with respect to $n$, we obtain $\mathrm{n}=0,794$. It is at such moments will be the same. When designing a superstructure, the same span moments will allow to obtain the same mounting blocks. The deviation of the span ratio even by a small amount dramatically increases the difference in the span bending moments, as shown in table 6 , which will require individual design of each block. Of course, it is not always possible to choose such spans that they satisfy the found ratio $\mathrm{n}=0.794$, because metal bridges are made of blocks equal to $21 \mathrm{~m}$. according to the recommendations of SP 35.13330.2011, Bridges and pipes [8], the authors also propose to assign the value of blocks equal to half of the normative module-10.5 meters, since it is convenient for the design, transportation and installation of most traditional bridge structures.

Table 6. Comparative characteristics the values of the span bending moments

\begin{tabular}{|c|c|c|c|c|}
\hline No. & Bridge circuit & $\boldsymbol{n}$ & $\boldsymbol{M}_{\text {extreme }}$ & $\boldsymbol{M}_{\text {middle }}$ \\
\hline 1 & $42+63+42$ & 0.666 & 15469 & 24700 \\
\hline 2 & $51+64+51$ & 0.797 & 24948 & 24557 \\
\hline 3 & $51.5+63+51.5$ & 0.817 & 25369 & 23660 \\
\hline
\end{tabular}




\begin{tabular}{|l|l|l|l|l|}
\hline 4 & $52.5+63+52.5$ & 0.833 & 26430 & 23400 \\
\hline
\end{tabular}

Thus, the division on the span of the continuous span structure should be not on the boundaries of the mounting blocks, but on the best ratio of the spans, as shown in the figure 3 .

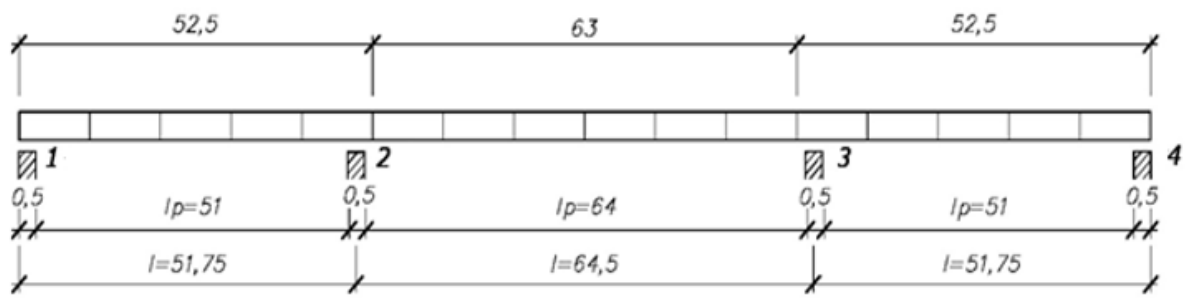

Fig. 3. Span structure with the division on the mounting blocks and spans

For the implementation of the proposals for the design of the bimetallic superstructure was considered a real bridge construction of the following dimensions: the length of the structure-168 m., the scheme of the bridge spans $51.75+64.5+51.75$; dimension $\mathrm{G} 10+$ pavement $2 \cdot 1.5+$ barrier fence $2 \cdot 0.45+$ railing $2 \cdot 0.2$. Thus, the width of the superstructure is $14,3 \mathrm{~m}$. the Superstructure of the bridge is all-metal with orthotropic plate and two main beams; the height of the wall is $2.3 \mathrm{~m}$. Loads and impacts: constant load $q_{\text {const }}=55,59 \mathrm{kN} / \mathrm{m}$, temporary vertical load for extreme span $q_{t}=54,48 \mathrm{kN} / \mathrm{m}$, load the middle of the span $q_{t}=49,416 \mathrm{kN} / \mathrm{m}[13,14]$. The supporting parts must be designed in accordance with the requirements $[15,16]$ and provide the necessary angular and horizontal displacements [17]. The reliability of the bridge structure is determined in accordance with [18].

Performing the necessary calculations of three-span continuous bridge (Fig. 3) for the constant and temporary loads [19,20] we obtain the enclosing diagrams of bending moments and transverse forces, shown in figure 4 . The calculations are given in tables 7,8 .

Table 7. Bending moments in sections of the bridge

\begin{tabular}{|c|c|c|c|c|c|c|c|}
\hline \multirow{2}{*}{ № section } & \multirow{2}{*}{$\mathbf{x}$} & \multirow{2}{*}{$\mathbf{M}_{\text {const }}$} & \multicolumn{3}{|c|}{ Temporary moments } & \multicolumn{2}{c|}{ Encompassing moments } \\
\cline { 4 - 8 } & & & $\mathbf{A 1 4} 1 \mathbf{s}$ & $\mathbf{A 1 4} 2 \mathrm{~s}$ & $\mathbf{A 1 4 ~ 3 ~ s}$ & Mmax & Mmin \\
\hline 1 & 0 & 0 & 0 & 0 & 0 & 0 & 0 \\
\hline 2 & 10 & 7890 & 9690 & -2202 & 473.7 & 18053.7 & 5688 \\
\hline 3 & 20.5 & 10100 & 13877 & -4515 & 971.1 & 24948.1 & 5585 \\
\hline 4 & 31 & 6010 & 11944 & -6827 & 1468.5 & 19422.5 & -817 \\
\hline 5 & 41.5 & -4310 & 3886 & -9140 & 1965.9 & 1541,9 & -13450 \\
\hline 6 & 51.5 & -19000 & -8682 & -11233 & 2415.9 & -16584.1 & -38915 \\
\hline 7 & 62 & -2910 & -6832 & 3100 & 566.2 & 756.2 & -9742 \\
\hline 8 & 72.5 & 6770 & -4893 & 11706 & -1283.4 & 18476 & 593.6 \\
\hline 9 & 83 & 9990 & -3132 & 14567 & -3133.2 & 24557 & 3724.8 \\
\hline
\end{tabular}


Table 8. Lateral forces in cross-sections of the bridge

\begin{tabular}{|c|c|c|c|c|c|c|}
\hline \multirow{2}{*}{$\begin{array}{c}\text { № } \\
\text { section }\end{array}$} & \multirow{2}{*}{ Qconst } & \multicolumn{2}{|c|}{ Temporary transverse forces } & \multicolumn{2}{c|}{ Enclosing transverse forces } \\
\cline { 3 - 7 } & & Q 1s & Q 2s & Q 3s & Q max & Q min \\
\hline 1 & 1072.3 & 1246.3 & -220.2 & 47.37 & 2366 & 852 \\
\hline 2left & -1818.6 & -1568.8 & -220.2 & 47.37 & -1771 & -3608 \\
\hline 2right & 1813.9 & 173.4 & 1612.4 & -173.4 & 3600 & 1640 \\
\hline 3left & -1813.9 & 173.4 & -1612.4 & -173.4 & -1640 & -3600 \\
\hline 3right & 1818.6 & -47.37 & 220.2 & 1586.8 & 3626 & 1771 \\
\hline 4 & -1072.3 & -47.37 & 220.2 & -1246.3 & -852 & -2366 \\
\hline
\end{tabular}

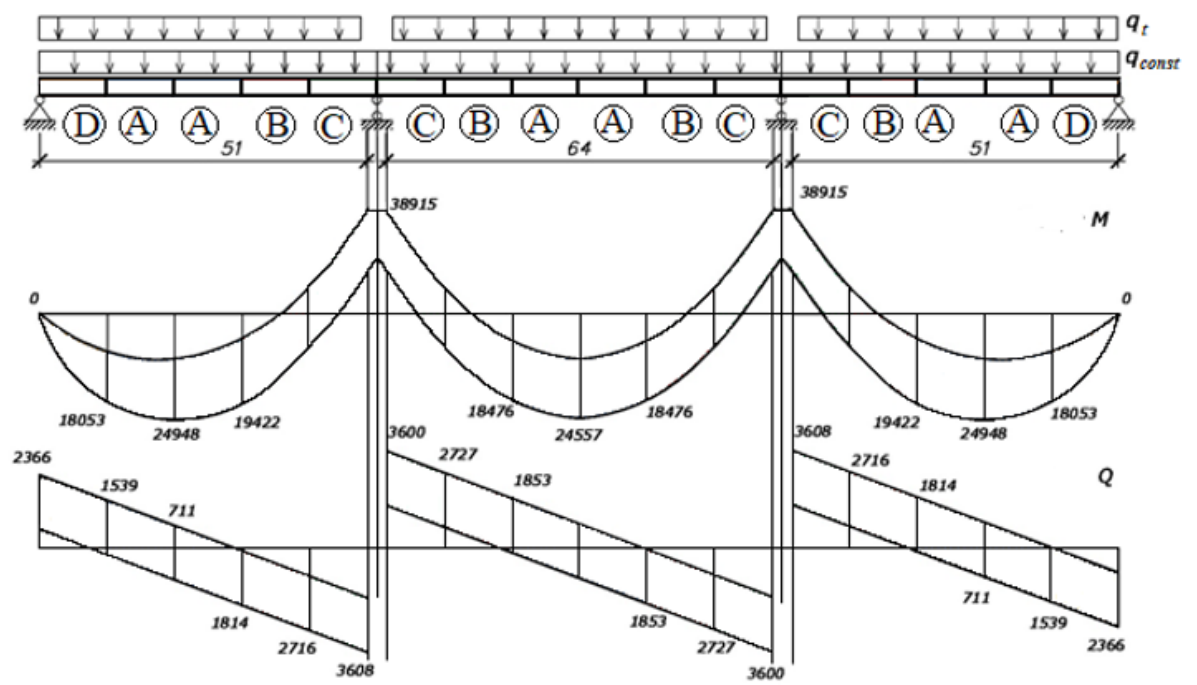

Fig. 4. Diagrams of bending moments and transverse forces with block marking.

If analyze the bending moment and transverse force diagrams shown in figure 4., it can be seen that the superstructure in this example is not difficult to make up of four modular blocks:

Block A is 21 meters long. here, the bending moment takes the maximum values $(\mathrm{Mmax}=24948 \mathrm{kNm})$, the values of the transverse force, on the contrary, the smallest $\left(\mathrm{Q}_{\max }=1853 \mathrm{kN}\right.$. $)$, in connection with which the lower belt can be made of steel S890QL.

The block B is 21 meters long. in this unit, the bending moment and transverse force take average values $\left(\mathrm{M}_{\max }=38915 \mathrm{kNm}\right.$ and $\left.\mathrm{Q}_{\max }=3660 \mathrm{kN}\right)$. In this block it is offered to carry out from steel S890QL the bottom belt, a wall of a beam and a Thong of an orthotropic plate in the Central part of the block 10 meters long (Fig. 5).

Extreme Block $\mathrm{C}$ and intermediate Block D length of $10.5 \mathrm{~m}$ in this case, you can design the same and reduce the number of typical blocks to three: A, B and C. in these areas, the minimum values takes the bending moment and the maximum - the transverse force $(\operatorname{Mmax}=19422 \mathrm{kNm}, \mathrm{Qmax}=2716 \mathrm{kN})$, they can be designed from steel S890QL 
lower belt and the wall of the beam. All other structural elements-sections, stiffeners, cross beams and connections to run of pavement steel 10XCRD.

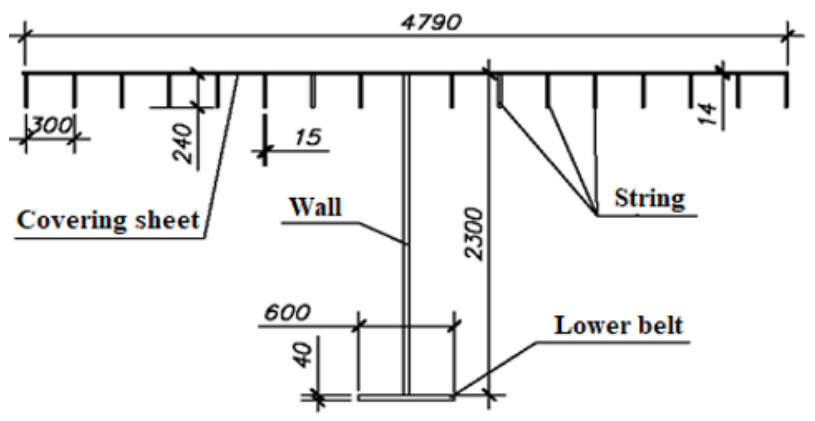

Fig. 5. Adduced cross-section of bimetallic beam

\section{Conclusions}

Based on the above, we can draw the following conclusions:

1. The division of the continuous structure should be made, taking into account the previously determined effective ratio of spans, aligning the bending moments;

2. The continuous bridge beam can be made of several standard blocks made of steels of different strength, which unifies and facilitates the manufacture of the structure, making it more durable and economical at the same time;

3. The use of high-strength steel reduces the complexity of the construction due to the reduction of technological operations and its own weight, allowing to reduce the consumption of steel, but given the increased cost, the most optimal is its use in those places where the greatest efforts are applied, while in other sections conventional steel is used, which makes it possible to design a structure more economical.

\section{References}

1. V.A. Volkov, M.V. Kulikova. Moscow Professor of the XVIII - early XX centuries. New science and technology. Moscow textbooks and map lithography. 294p. (Ed Yanus-K, Moscow 2003)

2. P.M. Salamakhin. Bridges and structures on the roads. Textbook for higher educational establishments: in 2 parts. Part 2. 344 p. (Ed Transport, Moskow 1991)

3. G.V. Skrylev. On the question of calculation reinforced concrete overbridge. Youth and scientific-and-technical progress in roadfield of south of Russia : Materials of X Intern. scientific and technical conference of students, postgraduates and young scientists (Volgograd, 18-20 of may 2016). Mode of access: http://vgasu.ru/publishing/on-line/. 113-116. (Ed VolgGASU, Volgograd, 2016)

4. A.V. Kalyuzhnyy, A.V. Makarov. The optimal shape of the superstructure of an iron bridge. Youth and scientific-and-technical progress in roadfield of south of Russia : Materials of XI Intern. scientific and technical conference of students, postgraduates and young scientists (Volgograd, 24-26 of may 2017). 30-32. (Ed VolgGASU, Volgograd, 2017)

5. M.M. Korneyev. Steel bridges: theoretical and practical guide to design. 547 p. (2003)

6. A.V. Makarov, M.A. Pavlova. Application of modern steels in bridge construction. Innovative science. 9. 14-16 (2018) 
7. A.V. Makarov. Dinamika i ustoychivost iskusstvennykh sooruzheniy. 16 p. (Volgograd, 2011)

8. SP 35.13330.2011 Mosty i truby. (Ed. Standartinform, Moskow, 2011)

9. Steel and alloy grades. URL: splav-kharkov.com/choose_type_class.php?type_id=3

10. GOST 19282-73 Low-alloy steel plate and wide-universal. Technical conditions. (Moskow, 1987)

11. Henan HZZ Iron and Steel Co., LTD ru.steel-grade-plate.com/carbon-and-low-alloyhigh-strength-steel-plate/en-10025-6/en-10025-6-s890ql-carbon-and-low-alloy-highst.html.

12. EN 10025: 2004 - Yevropeyskiy standart na izdeliya goryachekatanyye iz konstruktsionnykh staley. (2004)

13. A.V. Makarov, A.E. Kupreshchenkov. On the question of replacing concentrated loads with distributed ones. «Pure science» in the service of scientific and technological progress: collection of articles of the international scientific-practical conference. (23.12. 2017, Yekaterinburg). 75-78. (Ufa, 2017)

14. A.V. Makarov, A.E. Kupreshchenkov, V.S. Fedorov The feasibility of replacing the concentrated forces distributed in the calculation of arches. Sciense and education in the modern competitive environment: materials of articles of the international scientific-practical conference (Ufa, 27-28 of february 2018). 42-45. (Ufa, 2018)

15. A.V. Makarov, V.S. Karpov. Recommendations for the selection of support parts to increase the service life of the bridge structure. Engineering Herald of the Don. 1. /URL:ivdon.ru/ru/magazine/archive/n1y4079/20172017 (2017)

16.I.G. Ovchinnikov, V.I. Kononovich, A.V. Makarov. Damage and diagnostics of reinforced concrete bridge structures on roads. 92p. (Volgograd, 2004)

17. A.V. Makarov, A.V Zhuravlev. Flat deformations of bridge support parts. Engineering Herald of the Don. 1./URL:ivdon.ru/ru/magazine/archive/n1y2018/4707 (2018)

18. S.S. Rekunov. About an assessment of reliability and restoration of operational qualities of bridge constructions. Transport construction. V. 3. № 2. 7p. (2016)

19.V.A. Ignatyev, A.V. Makarov. A partial solution to the algebraic problem of eigenvectors and eigenvalues for problems of dynamics and stability of a private method-dynamic condensation. Construction mechanics and calculation of structures. 1. 14-20 (2005)

20. V.A. Pshenichkina, G.V. Voronkova, S.S. Rekunov. Research of the dynamical system “beam - stochastic base”. ProcediaEngineering. V. 150. pp. 1721-1728. (2016) 